\title{
Novel approach to endoscopic submucosal dissection using an additional working channel: a case report
}

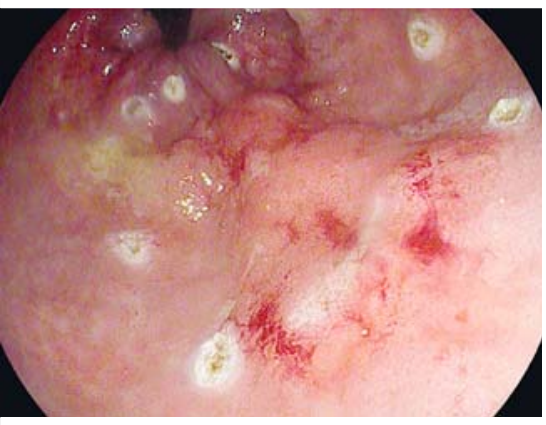

- Fig. 1 Nonpolypoid lesion on the resection scar following endoscopic submucosal dissection (ESD) of a mixed-type laterally spreading tumor of the rectum, marked for ESD using an external additional working channel.

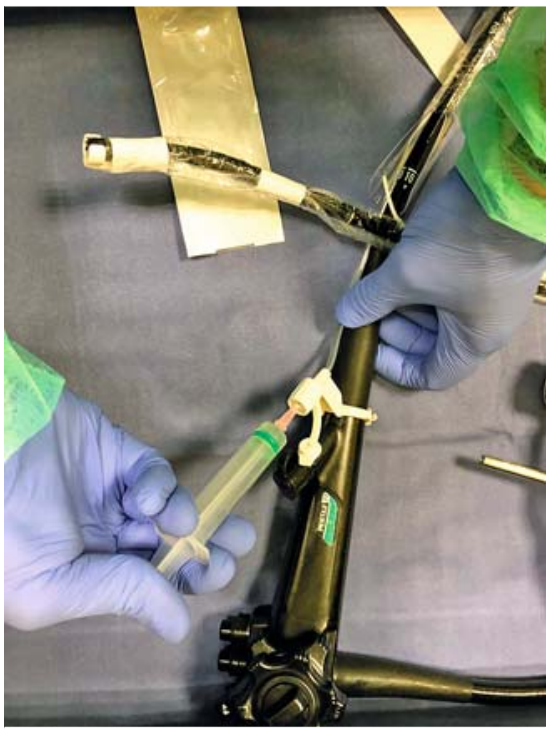

- Fig. 2 Additional working channel assembled over the scope.

A 72-year-old man underwent endoscopic submucosal dissection (ESD) of a 7-cm mixed-type laterally spreading tumor of the distal rectum, histologically defined as intramucosal adenocarcinoma. During subsequent surveillance, a 4-cm nonpolypoid lesion was detected on the resection scar ( $>$ Fig. 1). We performed a novel technique for ESD, using an external additional working channel
(AWC; Ovesco Endoscopy, Tübingen, Germany), called "ESD+," to eradicate the recurrent lesion ( Fig. 1, \Fig. 2 , - Fig. 3).

The procedure was conducted using a standard gastroscope. A HybridKnife I-Type (Erbe) dissector with saline solution (mixed with indigo carmine and adrenaline) as lifting fluid was used for the marking, incision, and partial dissection of the lesion. Subsequently, rescue forceps were introduced via the additional working channel to mobilize the lesion flap ( $\mathbf{F i g . 4 )}$ ) and complete the dissection ( $\mathbf{F i g . 5}$ ). This procedure allowed satisfactory exposure of the submucosal layer, ensuring safety and saving time in the resection of the whole lesion. The dissection was completed without complications ( $\triangleright$ Video $\mathbf{1}$ ).

While the use of rescue forceps via an additional working channel is widely recognized in the literature as a technique for endoscopic mucosal resection (EMR+) $[1,2]$, the ESD+ technique has been reported in vivo in only one recent case series, showing good results in terms of the timing and suitability of the procedure [3].

From our experience, an external working channel applied over the scope is a low-cost and safe device, and its use could improve the duration and technical feasibility of dissections of even quite large lesions without the need for a double-channel scope.

Endoscopy_UCTN_Code_TTT_1AQ_2AD

\section{Competing interests}

S. Danese has served as a speaker, consultant and advisory board member for ScheringPlough, AbbVie, Actelion, Alphawasserman, AstraZeneca, Cellerix, Cosmo Pharmaceuticals, Ferring, Genentech, Grunenthal, Johnson and Johnson, Millennium Takeda, MSD, Nikkiso Europe GmbH, Novo Nordisk, Nycomed, Pfizer, Pharmacosmos, UCB Pharma and Vifor.

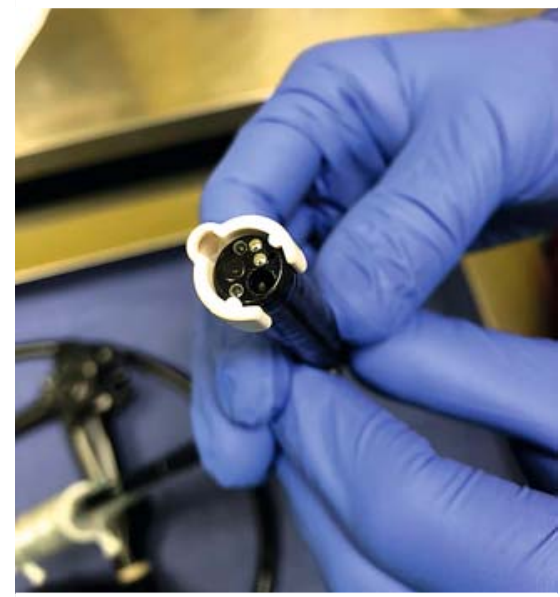

Fig. 3 Closer view of the additional working channel on the tip of the scope.

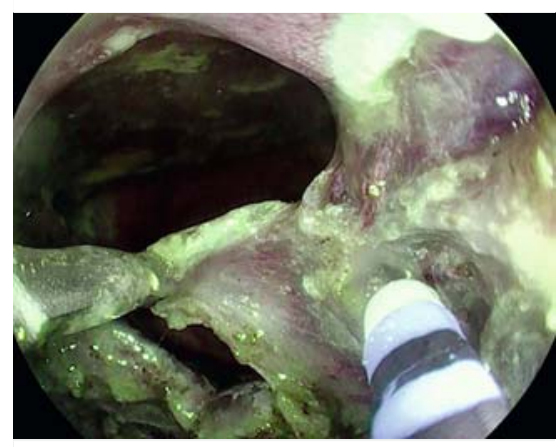

- Fig. 4 The rescue forceps helps the exposure of submucosal layer.

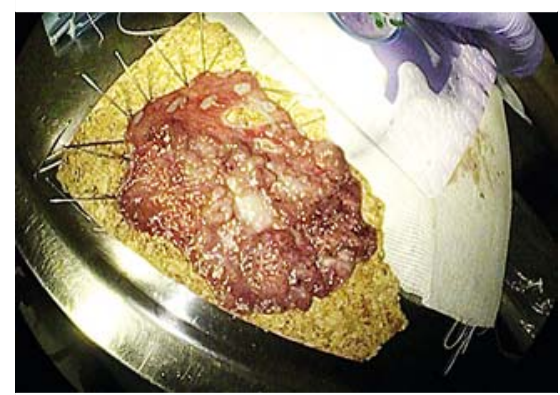

- Fig. 5 The resected lesion. 


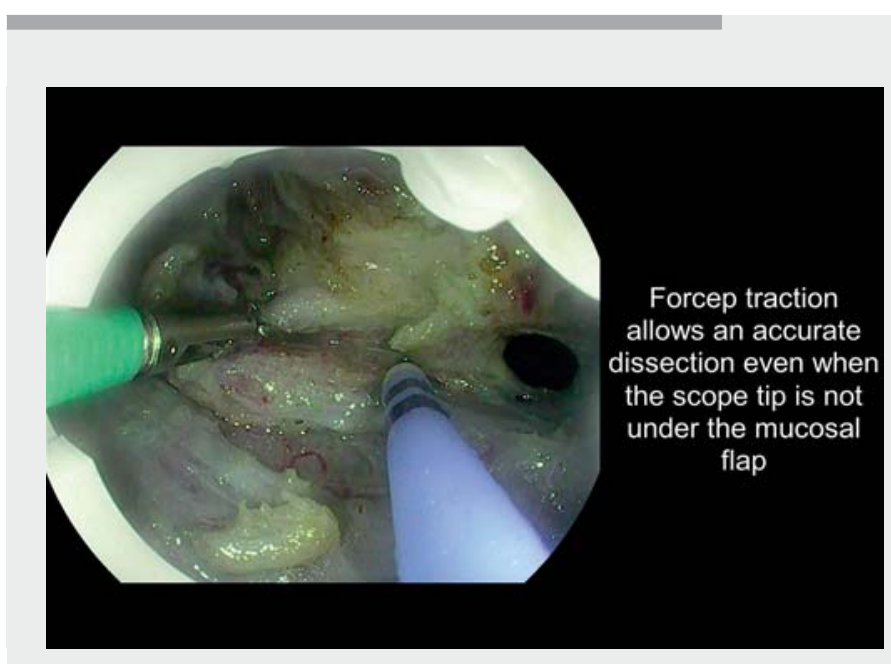

$\checkmark$ Video 1 Endoscopic submucosal dissection with an external additional working channel ("ESD+") to treat a recurrent lesion of the rectum.

The authors

\section{Francesco Azzolini, Francesco Vito}

Mandarino, Alberto Barchi, Paolo Biamonte, Maria Napolitano, Dario Esposito, Silvio

\section{Danese}

Division of Gastroenterology and

Gastrointestinal Endoscopy, Department of Experimental Oncology, IRCCS San Raffaele Scientific Institute, Vita-Salute San Raffaele University, Milan, Italy

\section{Corresponding author}

\section{Alberto Barchi, MD}

Division of Gastroenterology and

Gastrointestinal Endoscopy, Department of Experimental Oncology, IRCCS San Raffaele Scientific Institute, Vita-Salute San Raffaele University, Via Olgettina, 60, 20136 Milan, Italy

barchi.alberto@hsr.it
Bibliography

Endoscopy 2022; 54: E652-E653

DOI 10.1055/a-1732-7113

ISSN 0013-726X

published online 4.2.2022

(C) 2022. Thieme. All rights reserved.

Georg Thieme Verlag KG, Rüdigerstraße 14, 70469 Stuttgart, Germany

\section{ENDOSCOPY E-VIDEOS}

https://eref.thieme.de/e-videos

回店 Endoscopy E-Videos is an open access online section, 回辣: reporting on interesting cases and new techniques in gastroenterological endoscopy. All papers include a high quality video and all contributions are freely accessible online. Processing charges apply (currently EUR 375), discounts and wavers acc. to HINARI are available.

[1] Kantsevoy SV, Bitner M, Piskun G. New endoscopic platform for endoluminal en bloc tissue resection in the gastrointestinal tract (with videos). Surg Endosc 2016; 30: 31453151

[2] Wedi E, Knoop R, Jung C et al. EMR + with the AWC improves endoscopic resection speed compared to ESD: a porcine ex-vivo pilot study. Minim Invasive Ther Allied Technol 2021; 30: 47-54

[3] Walter B, Schmidbaur S, Krieger Y et al. Improved endoscopic resection of large flat lesions and early cancers using an external additional working channel (AWC): a case series. Endosc Int Open 2019; 7: E298-E301
This section has its own submission website at https://mc.manuscriptcentral.com/e-videos 